\title{
Study of Mortality and Autopsy findings amongst former Prisoners of the Japanese
}

\author{
Dr G Gill \\ MSc, MD, MRCP, DTM\&H \\ Senior Registrar, Freeman Hospital, Newcastle-on-Tyne
}

SUMMARY: Death certificates and/or autopsy reports from 180 former 2 nd World War prisoners of the Japanese were examined. The deaths occurred between 23 and 36 years after repatriation, and the mean age at death was 62.2 years. Causes of death were compared to government statistics, and there appeared to be an excess of deaths due to malignancy in the ex-POW group (especially carcinomas of stomach, pancreas and liver). Deaths due to ischaemic heart disease were slightly lower in the ex-POWs, and other causes of death were similar in both groups. The autopsy reports revealed one former POW who died as a result of chronic myocardial damage due to wet beriberi. Other such cases probably occurred, but were obscured by the coexistence of ischaemic or rheumatic heart disease.

\section{Introduction}

There has been recent interest in the continuing health problems of former Far East prisoners of war (FEPOWs), many of whom have persisting tropical conditions ${ }^{7},{ }^{8}, 12$ as well as altered patterns of other diseases ${ }^{6},{ }^{\prime}$ '. Mortality patterns, however, have not been investigated in detail in the U.K. In America, Cohen \& Cooper ${ }^{3}$ and later Nefzger ${ }^{-15}$ showed that ex-FEPOWs had an excess mortality in the early post-war years mainly due to tuberculosis, accidents and cirrhosis. This effect declined, until mortality was roughly equal to controls by the mid-1950s. Little information since has become available, and as the ex-FEPOWs are now in the 50-70 year age group, questions are arising as to whether they are experiencing increased mortality from conditions such as malignancies or ischaemic heart disease.

A related area of study concerns autopsy findings in ex-FEPOWs. Fisher ${ }^{5}$ reported post mortem findings in 11 Canadian ex-FEPOWs who had died soon after repatriation. Posterior column demyelination was found in seven, and "extensive loss of myelination" was present in the VIII nerve of one patient who had suffered nutritional deafness in captivity. A similar single case was reported by Crawford and Reid ${ }^{4}$. These workers gave pathological credence to the various nutritionally-induced neuropathic syndromes, clinically well known in the Far East prison camps $^{2}$. In addition a British former FEPOW has been reported, who died as a result of persistent cardiac damage due to wet beriberi whilst a prisoner, confirmed at autopsy ${ }^{10}$ some 30 years after release.

This study was carried out therefore, to investigate causes of mortality and autopsy findings amongst ex-FEPOWs in the UK today.

\section{Methods}

Ex-FEPOWs and their relatives, mainly from the $\frac{0}{\Phi} \underset{\omega}{c}$ North of England region, were circulated via their $\stackrel{\oplus}{+}$ 의 national and local FEPOW organisation, requesting, 끄 for research purposes, death certificates of former $\frac{\vec{\Phi}}{\stackrel{c}{D}}$ FEPOWs who had recently died.

When sent in these were then copied and returned to the relatives. If a post-mortem examination hado been carried out, the report of this was obtained when possible, with the permission of the relatives and pathologist involved. The period of collection of this information was over an approximate 18 month period between March 1980 and September 1981.

The major cause of death was extracted from the death certificate. This was usually the first mentioned disease (cause "I"), but if for example the certified cause was "bronchopneumonia due to metastatic bronchogenic carcinoma", then the latter cause was recorded. Incidence of the major causes of death were compared with figures from the Registrar General of Scotland 18 and the Office of Population, Censuses and Surveys of England and Wales $^{16}$ selecting figures for males of the nearest comparative age group.

\section{Results}

Details from 180 deaths certifications were analysed These comprised 176 death certificates (including 28 from which autopsy reports were obtained), and four autopsy reports alone. The mean age at death was 62.2 years (standard deviation 6.0 years) with a range of $49-81$ years. The deaths occurred from 1968 to 1981 inclusive (the mode was 1980 with 45 deaths in this year-35 years since repatriation from the Far East). 
Cause of Mortality

Table I lists the major causes of death amongst the ex-FEPOWs, together with comparative figures from Scottish and English government surveys ${ }^{16},{ }^{18}$. cardiac beriberi are fairly stereotyped, but are pathognomonic $^{1}$ 19. Amongst the deceased es FEPOWs in whom autopsy reports could not be traced, four had "myocardial fibrosis" entered on the

Table I

Major causes of death amongst 180 ex-FEPOWs compared to the general population

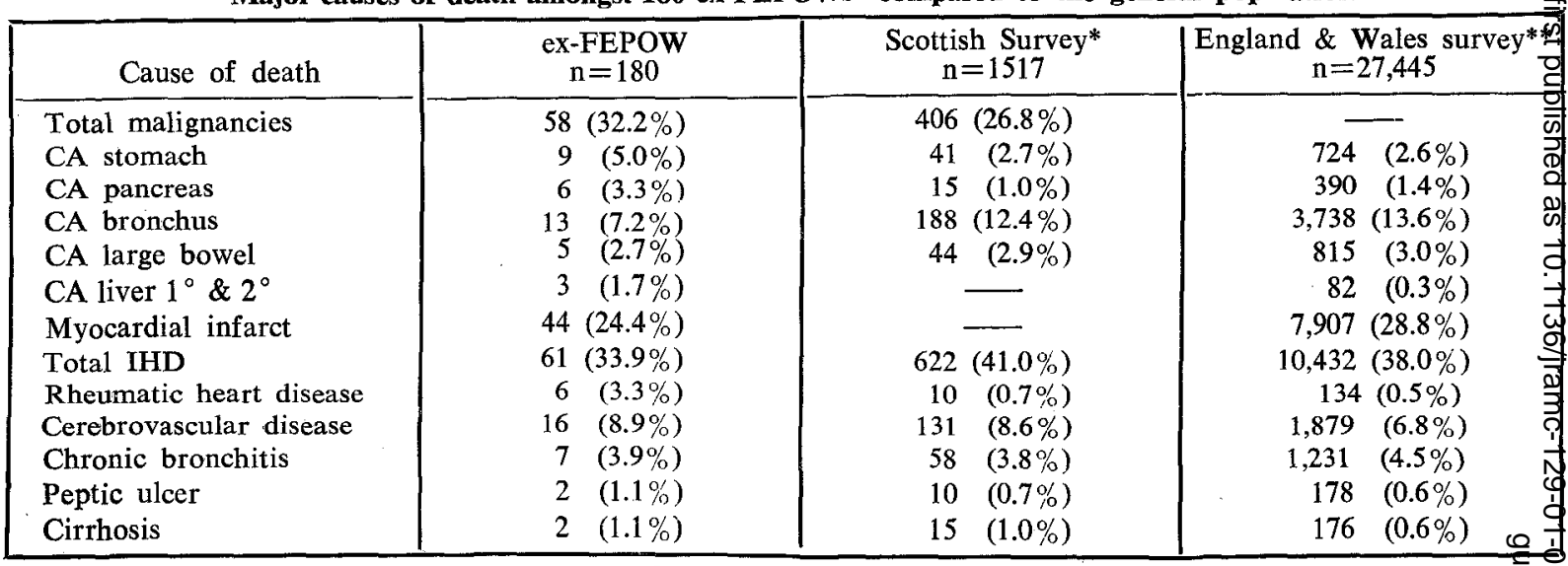

${ }^{*} Q$ uarterly returns of Registrar General of Scotland (HMSO, Edinburgh), last quarter 1973. Figures for males $\mathbb{8}_{g} \mathrm{C}_{\mathrm{C}}$ 55-64. ** Mortality Statistics 1979, England and Wales. Office of Population, Censuses \& Surveys (HMSO, London? Figures for males age 60-64. Abbrs. CA-carcinoma IHD-ischaemic heart disease.

\section{Autopsy Findings}

Amongst the 32 post-mortem reports, was the case of the ex-FEPOW with chronic cardiac beriberi, which has been reported in detail elsewhere ${ }^{10}$. This man died at the age of 60 years, 31 years after release from the Far East. He suffered severe wet beriberi whilst a POW, and soon after return developed atrial fibrillation and heart failure. This persisted and worsened over the years, eventually resulting in his death in 1976. At autopsy, the myocardium showed hypertrophy of muscle fibres and interstitial fibrosis consistent with long-standing damage from cardiac beriberi ${ }^{13}$, The coronary arteries were grossly and histologically normal.

A further possible case of persisting beriberi heart disease was also found amongst the autopsies, but was complicated by the presence of long-standing rheumatic mitral valve disease. The patient died in 1979 after a long history of heart failure, and subsequent histology of myocardium showed enlarged fibres with irregular nuclei, interstitial oedema, focal interstitial fibrosis and mononuclear infiltration. The sections were examined by several pathologists, who all agreed that the changes were unusual and possibly consistent with chronic cardiac beriberi. However, in the presence of long-standing rheumatic heart disease it was felt impossible to be sure.

The difficulty in this latter case is unfortunately common. Usually it is pre-existing ischaemic heart disease which makes the interpretation of myocardial fibrosis difficult. The histological changes induced by death certificate as a subsidiary cause of deatio where myocardial infarction was the major cas It seems likely that at least some of these cas may have represented long-standing cardiomyopat due to previous wet beriberi, with ischaemic hoge disease later superimposed.

No evidence of neuropathological changes duङे to nutritional neuropathy in the past was found, this is certainly because peripheral nerves, spina cord and cranial nerves are not routinely examined a autopsy. It is these tissues in which Fisher ${ }^{5}$ foun $\$$ marked demyelination in seven out of the 11 ex $\overrightarrow{\underline{6}}$ FEPOWs he examined.

\section{Discussion}

It is not possible to estimate total mortality rates amongst ex-FEPOWs in this country, as it is not known how many are alive today. There are als problems when looking only at causes of mortality Deaths amongst former servicemen or POWs are not routinely reported to the government. This surve $\vec{y}$ has utilised death certificates sent from relatives a the request of the National FEPOW Federation, and this may introduce some selective bias. It is also impossible to obtain an ideal control group, and on has to use government death statistics from the general population matched for sex and age. To give more accurate comparison, two government: surveys were used, from Scotland ${ }^{18}$ and from England and Wales ${ }^{16}$. Despite these difficulties, some interestru ing results have been obtained. 
It is firstly of interest that the mean age of death of the ex-FEPOWs was 62.2 years, which may indicate overall excess mortality in this group, or could possibly be due to selection (for example, if relatives were to particularly respond if the ex-POW had died early). Looking at the figures in detail there does seem to be an excess mortality in the malignancy group $(32.2 \%$ compared to $26.8 \%)$, due to marked increase of carcinoma of stomach, pancreas and liver (with surprisingly a reduction in carcinoma of the bronchus). One can only surmise as to possible causes, but dyspepsia (and probably achlorhydria) were common in the Far East prison camp, where the POWs called it "rice tummy" $17,20$. Chronic pancreatitis is also common in tropical countries ${ }^{14}$.

Evaluation of the high figure for death due to hepatic malignancy is difficult, as death certificates often do not differentiate between primary or secondary liver cancer. This problem, however, is shared by all three surveys, so the total figures are comparable. However, the increase in liver cancer in POWs could be due to metastatic deposits from stomach and pancreatic cancers (as these were markedly increased in the ex-FEPOWs) rather than primary hepatoma. It is unfortunate that this problem cannot be resolved, as increased mortality from hepatoma is an attractive possibility, since this was reported in the immediate post-war years ${ }^{3}$, and even now ex-FEPOWs have a greatly increased rate of hepatitis B surface antigen (HBsAg) carriage ${ }^{11}$.

The mortality figures for heart disease are also of interest. The ex-FEPOWs had a markedly increased mortality due to rheumatic heart disease $(3.3 \%$ compared to $0.7 \%$ and $0.5 \%$ in the control surveys), presumably because of rheumatic fever suffered whilst in captivity. For ischaemic heart disease there is an interesting slight but consistent decrease in the exFEPOW group, both for myocardial infarction and "total IHD" (see Table I). It is fascinating that Freed \& Stringer $^{21}$ reported decreased mortality from IHD amongst Australian ex-FEPOWs up to 1963, though this was not confirmed in American surveys $^{15}$. One could hypothesise that a prolonged period of near-starvation may protect from coronary artery disease, but this is of course purely speculative.

British former FEPOWs have excess morbidity from chronic lung disease and peptic ulceration ${ }^{9}$, but mortality figures in this survey are comparable to controls. Results of cirrhosis, cerebrovascular disease, and other less frequent causes of death, are not significantly different from controls.

The experience of imprisonment in the Far East during the 2nd World War has obviously had lasting effects on morbidity and mortality of the survivors. Time is running out for further study of this fascinat- ing group, which is surely indicated both for the benefit of this deserving group of men, and also for intrinsic scientific interest.

\section{REFERENCES}

1 Benchimol A B, Schlessinger P. Beriberi heart disease. Am Ht J. 1953; 46: 245-263.

3 COHEN B M, COOPER M Z. A follow-up of World War II prisoners of war. 1954; V A Medical Mongraph: Washington D C (US Gov't Printing Office, Washington $25 \mathrm{DC}$ ).

2 Clarke C A, SNedDon I B. Nutritional neuropathy in prisoners of war and internees from Hong Kong. 1946; 1: 734-737.

4 Crawford J N, Reid J A G. Nutritional disease affecting Canadian troops held prisoner of war by the Japanese. Canad J Res 1947; 25E: 53-85.

5 FISHER M. Residual neuropathological changes in Canadians held prisoners of war by the Japanese. Canada Serv Med J 1955; 11: 157-199.

6 GibBerd F B, SimmondS J P. Neurological disease in ex-Far East prisoners of war. Lancet 1980; 2: 135-137.

7 GILL G V, BELL D R. Strongyloides stercoralis infection in former Far East prisoners of war. Brit Med J 1979; 2: 572-574.

8 GILl G V, Bell D R. Persisting tropical diseases amongst former prisoners of war of the Japanese. Practitioner 1980; 224: 801-803.

9 GILL G V, BELL $D$ R. The health of former prisoners of war of the Japanese. Practitioner 1981; 225: 531-538.

10 Gill G V, Henry L, ReId H A. Chronic cardiac beriberi in a former prisoner of the Japanese. Brit J Nutr 1980; 44: 273-274.

11 Gill G V, Selkon J B, Mortimer P P, VanderVELDE $E$. M. Hepatitis $B$ infection in former prisoners of the Japanese. Lancet 1980; 2: 918.

12 GRove D I. Strongyloidiasis in allied ex-prisoners of war in South-East Asia. Brit Med J 1980; 1: 598601.

13 Jervey L P. Prolonged myocardial disease due to beriberi with necropsy after 18 years. $A m J 1957$; 54: 621-624.

14 LANCET. Diabetes, cyanide and rat poison. Leading article Lancet 1979; 2: 341-342.

15 Nefzger M D. Follow up studies of World War II and Korean War prisoners, I study plan and mortality findings. Am $J$ Epidem 1970; 91: 123-138.

16 Office of Population, Censuses and Surveys. Mortality Statistics 1979, England and Wales. HMSO London; 1979.

17 O'Regan J A R. Prisoners of war from Singapore - a medical report. New $Z$ Med $J$ 1945; 44: 329 334.

18 Registrar General of Scotland. Quarterly Returns 1973. HMSO Edinburgh: 1973.

19 Schlessinger P, Benchimol A B. Cardiac beriberi simulating arteriosclerotic heart disease. $\mathrm{Am} \mathrm{Ht} J$ 1951; 42: 801-808.

20 SMith D A, Woodruff M F A. Deficiency diseases in Japanese prison camps. Med Res Coun Special Report Series No. 274; HMSO London: 1951.

21 Freed G, STRINGer P B. Comparative mortality experience 1946-1963 among former Australian prisoners of war of the Japanese. Repatriation Dept Cent Med Res Advisory Committee Melbourne Aust 1968. 